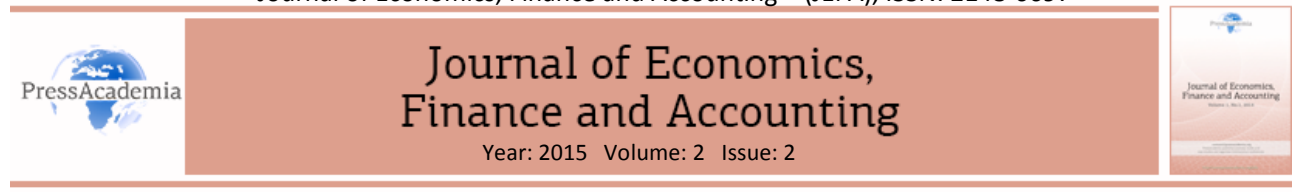

\title{
A STUDY FOR THE INTERACTION BETWEEN RISK PREMIUMS AND STOCK EXCHANGE IN DEVELOPING COUNTRIES
}

\section{DOI: 10.17261/Pressacademnia.2015211508}

\section{Sedat Yenice', Adalet Hazar ${ }^{2}$}

${ }^{1}$ Gazi University. sedatyenice@gmail.com

${ }^{2}$ Akademi Egitim. adalethazar@gmail.com

\section{Keywords}

Country risk premium, credit default swaps, CDS, stock index, regression.

JEL Classification

G15, G20

\begin{abstract}
This study attempts to examine the interaction of credit default swap (CDS), which stands for risk premium, with the stock exchanges of developing countries. To this end, 5-year CDS premiums belonging to Turkey, Argentina, Brazil, Indonesia, Malaysia, and China were obtained on a daily basis between April 2009 and April 2014 and were compared with stock exchange index closes in the same period. Data were analyzed via regression curve estimation models. Insignificant relationships were found between CDS premiums and index closes in 2 of 6 countries while significant relationships were found in other countries. It was concluded that investors investing in developing countries that have an investment potential take into consideration CDS premiums as country risk.
\end{abstract}

\section{GELIŞMEKTE OLAN ÜLKELERDEKI RISK PRIMLERI ILE MENKUL KIYMET BORSALARININ ETKILEŞIMININ INCELENMESi ${ }^{1}$}

\section{Anahtar Kelimeler \\ Ülke risk primleri, kredi temerrüt swapları, CDS, borsa endeksi, regresyon.}

\section{JELSınıflandırması G15, G20}

\begin{abstract}
ÖZET
Bu çalışmada, risk primini temsil eden Kredi Temerrüt Swap'ının (CDS) gelişmekte olan ülkelerin menkul kıymet borsaları ile etkileşimi incelenmeye çalışılmaktadır. Çalışma kapsamında Türkiye, Arjantin, Brezilya, Endonezya, Malezya ve Çin olmak üzere 6 ülkeye ait 5 yıllık CDS primleri Nisan 2009 - Nisan 2014 dönemleri arasında günlük olarak temin edilmiş ve aynı döneme ait menkul kıymet borsa endeks kapanışları ile karşılaştırılmıştır. Çalışmada yöntem olarak Regresyon Eğrisi Tahmini Modelleri kullanılarak veriler analiz edilmeye çalışılmıştır. Çalışmanın sonunda elde elden bulgulara göre, CDS primleri ile endeks kapanışları arasında 6 ülkeden 2'sinde önemsiz ilişkiye rastlanırken, diğer ülkelerde önemli kabul edilebilecek ilişkiler tespit edilmiştir. Çalışmada, gelişmekte olan ve yatırım potansiyeli taşıyan ülkelere yatırım yapan yatırımcılar ülke riski olarak CDS primlerini dikkate aldığı sonucuna ulaşılmıştır.
\end{abstract}

\footnotetext{
${ }^{1}$ Bu çalışma Pamukkale Üniversitesi tarafından 15 - 18 Ekim 2014'de Denizli'de gerçekleştirilen 18. Ulusal Finans Sempozyumunda bildiri olarak sunulmıştur.
} 


\section{GiRiş}

Finansal piyasalar açısından ülke risk primlerinin tespit edilmesi o ülkeye yapılacak olan doğrudan ve dolaylı yatırımları etkilemektedir. Yatırımcılar yapacakları yatırımların riskliliğini tespit ederek bu riskliliğe göre yatırım yapma yada yapmama güdüsüyle hareket ederler. Aynı zamanda yapılması düşünülen yatırım için getiri beklentisi de risk beklentisi çerçevesinde oluşturulmaktadır. Dolayısıyla ülkenin risk priminin tespit edilmesi finansal piyasalardaki yatırımları etkilemektedir.

Genellikle yabancı yatırımcılar yatırım yapacakları ülkenin riskliliğini rating kuruluşlarının belirlemiş olduğu ülke notlarını baz alarak ölçmektedirler. Ancak rating notlarının açıklanması sürekli bir işlem olmayıp, genellikle belirli periyotlarla gerçekleşmektedir. Bu da ülke riskine ilişkin bilginin güncelliği konusunda zaman zaman yetersiz kalabilmektedir. Öncelikle yatırım yapmak isteyenler yatırım kararı verirken, yatırım yapacakları ülkenin risk priminin güncel olmasına özen göstermektedirler. Rating kuruluşlarından sağlanan ülke notları ise bu isteğe her zaman yanıt veremeyebilmektedir. Bu nedenle yatırımcılar ülke riskine ilişkin bilgilenmede yeni gösterge arayışına girmektedir.

Kredi riski, bir tarafın sözleşmedeki ödeme yükümlülüğünü yerine getirememesi olarak tanımlanmaktadır. Bu risk, bir tarafın diğer tarafa gelecek dönemdeki ödemeler için yükümlülük altına girmesi ile var olmaktadır. Bahsedilen ödeme yükümlülüğünün yerine getirilmemesi ise temerrüt olarak adlandırılmaktadır. (Ersan ve Günay, 2009:3) Kredi riski alacaklı tarafı önemli bir risk altına soktuğundan bu riskten korunmak amacıyla kredi türevleri kullanılmaktadır.

Kredi türevleri en basit tanımıyla piyasa katılımcılarının karşılıklı imzalamış oldukları sözleşmelerdir. Diğer tüm türev ürünlerde olduğu gibi amaç temelde riski azaltmaktır, ancak spekülatif amaçla da kullanılabilir. Kredi türevlerinin tanımlarıyla ilgili olarak en başta yapılan vurgu, iki taraflı sözleşme niteliğinde olmalarıdır. Sözleşmenin esası, kredi riskinin bir taraftan diğerine aktarılmasına dayanmaktadır. (Tözüm, 2009:11)

Karabıyık ve Anbar (2006)'a göre kredi türevleri, kredi riskini diğer risk türlerinden ayırmak ve karşı tarafa düşük maliyetle transfer etmek için kullanılmaktadır. Ayrıca diğer türev ürünlerde olduğu gibi kredi türevleri de riskten korunma dışında spekülasyon ve arbitraj amaçlı da kullanılmaktadır. Kredi türevlerinin başlıca kullanıcıları bankalar, portföy yönetim şirketleri ve sigorta şirketleridir.

Literatürde kredi türevlerinin çeşitleri ile ilgili değişik görüşler olmasıyla beraber kredi türevleri genellikle 5 çeşit başlık altında toplanmaktadır. Bu türevler kredi temerrüt swapları, toplam getiri takası, kredi spread opsiyonları, krediye dayalı tahviller ve teminatlı borç yükümlülükleridir. Kredi türevleri içerisinde en çok kullanılan ve toplam işlem hacmi içerisinde önemli bir paya sahip olan kredi türevi türü ise, Kredi Temerrüt Swapları'dır. (Karabıyık ve Anbar, 2006: 50)

Kredi Temerrüt Swapı en dar anlamıyla kredi riskini etkin bir biçimde yönetme amacı taşıyan bir çeşit finansal sözleşme, en geniş tanımıyla ise herhangi bir finansal kredinin geri ödenmeme riskine karşı alacaklı tarafın parasını koruma altına alan, bunu da belirli bir bedel karşılığında yapan kredi türev aracıdır. (Kunt ve Taş, 2009:80) 
Başka bir tanıma göre ise, Kredi Temerrüt Swapı (CDS), tanımlanan bir kredi riskini bir taraftan diğer bir tarafa transfer eden, iki taraflı bir tezgahüstü sözleşmedir. (Alper, 2011: 79) CDS sözleşmeleri, kredi riskini borçlu dışında üçüncü tarafa transfer etmek amacıyla geliştirilen özel kredi türev ürünleridir ve işleyişi aşağıdaki şekilde gösterilmiştir.

\section{Şekil 1: Kredi Temerrüt Swap İşleminin İşleyişi}

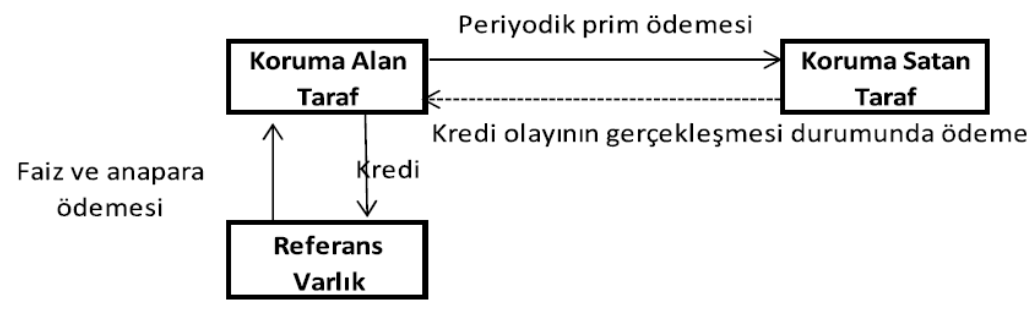

Kaynak: (Turguttopbaş, 2013: 38 - 39)

Şekilden de görüldüğü gibi kredi temerrüt swapı, koruma satın alan taraf ile koruma satan taraf arasında gerçekleştirilmektedir. Kredi temerrüt swapı işleminde, koruma satın alan taraf referans varlık üzerinden almış olduğu krediye ilişkin riski, belirli bir prim karşılığında koruma satan tarafa devretmektedir.

Kredi riskini karşı tarafa yansıtmak için yaygın olarak kullanılan CDS'ler, aynı zamanda ülkenin riskinin de göstergesi olmaktadır. Teorik olarak ideal bir ortamda CDS spreadleri ile tahvil piyasasındaki risk primleri her iki piyasanın entegrasyonuna bağlı olarak arbitraj imkanı nedeniyle benzer şekilde hareket etmektedir. Bu nedenle CDS spreadlerinin finansal sıkıntının daha uygun bir piyasa göstergesi olduğu ifade edilmektedir. (Alper, 2011:84)

Bu açıklamaların ışığı altında çalışmada çeşitli ülkelere ait CDS primleri ülke risk primlerinin bir ifadesi olarak dikkate alınarak, bu risk primleri ile ülkelerin menkul kıymet borsalarına ait endeks kapanış verileri karşılaştırılarak aralarındaki etkileşim belirlenmeye çalışılacaktır. Bu araştırmada ekonomisi çok hasas olan ülkelerde CDS primleri ile borsa endeksleri arasında yüksek duyarlılık beklenmekte olup, çalışmadan bu yönde bulgular elde edilmesi beklenilmektedir.

\section{LITERATÜR TARAMASI}

Çalışmanın konusunu oluşturan CDS'ler ile finansal piyasalar arasındaki ilişkiyi ortaya koymak için yapılan yazın taramasında çeşitli yerli ve yabancı çalışmaya rastlanmıştır. Yapılan yazın taraması sonucunda elde edilen çalışmalar ve sonuçlarının bir kısmı aşağıda belirtilmiştir.

Sensoy ve diğerleri (2014) çalışmalarında yatırımcıların başlıca Avrupa ülkeleri ve Türkiye'ye karşı zamanla değişkenlik gösteren risk algıları ilişkilerini incelemişlerdir. Çalışmada Eylül 2004 ve Nisan 2013 döneminde Türkiye ve 13 Avrupa ülkesinin kredi temerrüt takası (CDS) marjları arasındaki dinamik koşulsal korelasyonlar elde edilmiş, daha sonra panel karşılaştırma yöntemi kullanarak, bu dinamik korelasyon seviyelerindeki değişkenlikleri içsel olarak tespit etmişlerdir. Çalışmanın sonucunda Türkiye'nin küresel finansal koşullara karşı bağışıklığı olmadığını ve küresel mali krizden sonra Türkiye ve başlıca Avrupa ekonomileri arasında risk algısı bakımından entegrasyon bulunduğunu ortaya koyulmuştur. 
Keten, Başarır ve Kılıç (2013) çalışmalarında Türkiye için CDS primlerini etkileyen küresel faktörleri analiz etmişlerdir. Çalışmada Türkiye'nin 5 yıllık CDS pirimi ile bu primi etkileyeceği düşünülen finansal değişkenler arasındaki ilişki VAR modeliyle tahmin edilmeye çalışılmıştır. Çalışmanın sonucunda belirlenen değişkenler ile CDS primleri arasında uzun dönemli bir ilişki oldu tespit edilmiştir.

Hassan ve diğerleri (2013) çalışmalarında doğrusal regresyon kullanarak ABD, Avrupa ve Asya - Pasifik piyasalarında kredi temerrüt takası marjlarının belirleyicilerini yeniden incelemişlerdir. Çalışmaya göre, Amerika Birleşik Devletleri ve diğer ülkelerden elde edilen bulgular, CDS'in gerçek piyasa değerlemesi ve temerrüt riskinin teorik belirleyicileri arasında var olan önemli ilişkiyi doğrulamaktadır.

Balı ve Yılmaz (2012) çalışmalarında CDS marjları ile IMKB 100 endeksi arasındaki ilişkiyi ortaya koymaya çalışmıştır. Bu kapsamda, Ocak 2002 - Nisan 2012 dönemi için haftalık bazda endeks kapanış tutarları ile CDS marjları arasındaki ilişki analiz edilmiştir. Çalışmada, endeks ile CDS marjları arasında ters yönlü bir korelasyon tespit edilmiştir.

Chen, Hammoudeh ve Yuan, (2011) çalışmalarında bir eşik etkisinin varlığında, üç finansal sektörün (bankacılık, mali hizmetler ve sigorta) kredi temerrüt takası (CDS) sektör endekslerinin uzun vadedeki dengesi için yapılan asimetrik ayarlamalarını incelemişlerdir. Çalışmanın bulgularına göre momentum-eşik otoregresyon (MTAR) modellerinin sonuçları, bu üç CDS endeksinden oluşan tüm çiftlerde asimetrik eş-bütünleşmenin var olduğunu göstermektedir. Çalışmanın sonuçlarına göre uzun vadede uyum sağlama hızı, eşiğin altında ayarlamalar durumunda diğer tüm çiftlerden daha yüksektir.

Terzi ve Ulucay (2011) çalışmalarında mali kriz döneminde kredi temerrüt takasının (CDS) rolünü araştırmıştır. Yazarlara göre CDS'ler, piyasa katılımcılarının riski aktarabilmesine veya dağıtabilmesine olanak sağlayan ara araçlardır. Ayrıca yazarlara göre şeffaf olmayan yapısı, yoğunlaşması, birbirleriyle bağlantılılığı ile birleştiğinde CDS piyasasının büyüklüğünün; mali piyasa istikrarına sistematik bir risk olabileceğinin işareti olabileceğini tespit etmişlerdir. Yazarlar araştırmada, piyasa istikrarına kredi temerrüt takası piyasasının etkisinin, pazarlardaki piyasa mekanizmalarına ve sermaye - likidite gerekliliklerine bağlı olduğu sonucuna ulaşmışlardır.

Norden ve Weber (2009) çalışmalarında 2000-2002 yılları arasındaki dönemde kredi temerrüt takası (CDS), tahvil ve borsa piyasalarındaki ilişkiyi incelemişlerdir. Çalışmada aylık, haftalık ve günlük ileri-geri ilişkileri ve eş-bütünleşmeden kaynaklanan piyasalar arası düzenlemeleri incelemiştir. Çalışmada ilk olarak, borsa getirilerinin CDS ve tahvil marj değişikliklerini yönlendirdiği görülmüştür. İkinci olarak ise, CDS marj değişikliklerinin çok sayıda şirket için tahvil marj değişikliğine neden olduğunu ve bunun tersinin de geçerli olduğu tespit edilmiştir. Çalışmada yazarlar üçüncü olarak CDS piyasasının, tahvil piyasasına oranla borsaya daha duyarlı olduğunu ve birlikte hareketin gücünün, daha düşük kredi kalitesini ve tahvil ihracını artırdığını tespit etmişlerdir.

Ayrıca yazarlar Norden ve Weber (2004)bir diğer çalışmalarında 2000-2002 döneminde üç büyük derecelendirme kuruluşu tarafından yapılan derecelendirme duyurularına borsa ve kredi temerrüt takası (CDS) piyasalarının verdiği tepkiyi analiz etmektedirler.

Vaka inceleme metodolojisi uygulayarak, anormal getiriler bakımından bu piyasaların tepki verip vermediğini, ne kadar tepki verdiğini ve CDS marjı değişikliklerine nasıl adapte olduğunu 
incelemişlerdir. Çalışmada ilk olarak, iki piyasanın da derecelendirmelerdeki düşüşü sadece beklemediğini, ayrıca bu üç kuruluşun derecelendirme düşüşlerini gözden geçirdiklerini gözlemlemişlerdir. İkinci olarak, derecelendirme kuruluşlarının kendi içindeki ve kuruluşlararası farklı derecelendirme vakalarının birleştirilmiş analizi, Standard \& Poors ve Moody's'in not düşürme değerlendirmelerinin her iki piyasa üzerinde de en fazla etkiyi gösterdiğini ifade etmişlerdir. Araştırmanın üçüncü bulgusu ise her iki piyasadaki anormal performans büyüklüğü, eski derecelendirme seviyesinden, önceki derecelendirme vakalarından ve sadece CDS piyasasında tüm kuruluşların vaka öncesi ortalama derecelendirme seviyesinden etkilendiğidir.

Fung ve diğerleri (2008) çalışmalarında 2001-2007 döneminde, ABD borsası ve kredi temerrüt takası (CDS) piyasası arasındaki pazar çapındaki ilişkileri incelemişlerdir. Çalışmanın bulguları $A B D$ borsası ve CDS piyasası arasındaki ileri - geri ilişkinin, vurgulanan referans varlığın kredi kalitesine bağlı olduğunu göstermektedir. Çalışmada borsa fiyatlandırma sürecinde CDS endeksinin yatırım derecesini yönlendirirken, fiyatlandırma ve volatilite bakımından borsa ve yüksek getirili CDS piyasası arasında önemli bilgi geribildirimi sağladığı tespit edilmiştir. Çalışmada piyasa katılımcılarının alım satım ve/veya risk dengelemesi yapmadan önce her iki piyasada da bilgi araştırması yapmaları gerektiği sonucuna ulaşılmıştır.

Zhu (2006) çalışmasında tahvil piyasası ve hızla büyüyen kredi temerrüt swapı (CDS) piyasasındaki kredi riskinin fiyatlandırılmasını karşılaştırmaktadır. Yazara göre eş-bütünleşme testi, iki kredi marjı arasındaki teorik parite ilişkisinin uzun vadeli bir denge durumu bulundurduğunu doğrulamaktadır. Yazara göre kısa vadede paritede önemli oranda sapma meydana gelebilir. Yazar uyguladığı panel veri çalışması ve VECM analizi ile bu sapmanın büyük oranda CDS primleri ve kredi koşullarındaki değişikliklere duyarlılıktan kaynaklandığı sonucuna ulaşmıştır.

\section{VERILER VE METODOLOJi}

\subsection{Veriler}

Çalışmanın analiz kısmında gelişmekte olan ülkelere ait borsa endeksi kapanış değerleri ve ülkelerin CDS verileri arasında ilişki kurulmaya çalışılmıştır. Bu kapsamda 7 ülkeye ait veriler Nisan 2009 ile Nisan 2014 itibariyle iş günü olarak toplanmıştır. Veri setindeki gözlem sayısı her ülkedeki resmi tatil sayısı değişkenlik gösterdiğinden Türkiye için 1261 gözlem, Rusya için 1254 gözlem, Arjantin için 1220 gözlem, Brezilya için 1242 gözlem, Endonezya için 1261 gözlem, Malezya için 1238 gözlem ve Çin için 1247 gözlem kullanılmıştır.

Ülke bazında 5 yıllık CDS'ler günlük olarak ve Amerikan Doları bazında datastream programından temin edilmiştir. Ülkelere ait borsa endeks kapanışları ise yahoo finance 2 web sayfasından elde edilmiştir.

Endeksler belirlenirken gösterge endeksler tercih edilmiş olup, Türkiye için ISE 100 endeksi, Rusya için RTSI endeksi, Arjantin için MERVAL endeksi, Brezilya için IBOVESPA endeksi, Endonezya için IDX endeksi, Malezya için $\mathrm{KLCl}$ endeksi ve Çin için SSECOMP endeksi kullanılmıştır.

\footnotetext{
${ }^{2}$ http://finance.yahoo.com
} 
Analizde kullanılan veriler aşağıdaki şekilde kısaltılmıştır;

Türkiye CDS Primleri = turkiyecds

Türkiye ISE100 Endeks Kapanış = turkiyekapanis

Rusya CDS Primleri = rusyacds

Rusya RTSI Endeks Kapanış = rusyakapanis

Arjantin CDS Primleri $=$ arjantincds

Arjantin MERVAL Endeks Kapanış = arjantinkapanis

Brezilya CDS Primleri =brezilyacds

Brezilya IBOVESPA Endeks Kapanış = brezilyakapanis

Endonezya CDS Primi = endonezyacds

Endonezya IDX Endeks Kapanış = endonezyakapanis

Malezya CDS Primleri = malezyacds

Malezya $\mathrm{KLCl}$ Endeks Kapanış =malezyakapanis

Çin CDS Primi $=$ cincds

Çin SSECOMP Endeks Kapanış = cinkapanis

Veriler analize hazır hale getirilirken CDS primlerinin ve endeks kapanışlarının tarihleri uyumlaştırılmış, bu nedenle sadece ilgili ülkedeki işgünü verileri analize dahil edilmiştir. Kapanış verileri her ülkenin kendi para biriminden, CDS primleri ise Amerikan Doları bazında temin edilmiş olup, bu durumun analiz sonucunda bulunan sonuçlarda değişiklik oluşturmayacağı düşünüldüğünden veriler herhangi bir düzeltme işlemine tabi tutulmamıştır.

\section{2. İstatistiksel Yöntem}

Çalışmada yöntem olarak Regresyon Eğrisi Tahmini Modelleri kullanılarak veriler analiz edilmeye çalışılmıştır. Bir veya daha fazla eğrinin tahmin modelleri regresyon analizi ile elde edilebilmektedir. Çalışmada veriler analiz edilirken her ülke için CDS primleri bağımsız değişken, endeks kapanışları ise bağımlı değişken olarak dikkate alınıp her ülke için tek tek model oluşturulmuştur.

Bağımsız değişkenin bağımlı değişkeni açıklamada yeterli olup olmadığı sorusunun cevabı belirleme katsayısı kavramıyla ifade edilmektedir. Belirleme katsayısı $\mathrm{R}^{2}$ ile gösterilmektedir. $R^{2}$; 0 ile 1 arasında değişmektedir. $\left(0 \leq R^{2} \leq 1\right) R^{2}$ değeri $1^{\prime}$ e yaklaştıkça bağımsız değişkenin bağımlı değişkeni daha iyi açıklamakta olduğu ifade edilmektedir. (Erbaş, 2013, s.488)

Çalışmada aşağıda formülleri verilen eğri tahmin yöntemleri tek tek değerlendirilerek en uygun olanı değişkenler arasındaki ilişkiyi açıklamak açısından kullanılmıştır.

Linear: $Y=b 0+(b 1 * t)$.

Logarithmic: $Y=b 0+(b 1 * \ln (t))$.

Inverse. $Y=b 0+(b 1 / t)$. 
Quadratic. $Y=b 0+(b 1 * t)+(b 2 * t 2)$.

Cubic. $Y=b 0+(b 1 * t)+(b 2 * t 2)+(b 3 * t 3)$.

Power. $\mathrm{Y}=\mathrm{b} 0 *(\mathrm{t} * * \mathrm{~b} 1)$ veya $\ln (\mathrm{Y})=\ln (\mathrm{b} 0)+(\mathrm{b} 1 * \ln (\mathrm{t}))$.

Compound. $\mathrm{Y}=\mathrm{b} 0 *(\mathrm{~b} 1 * * \mathrm{t})$ veya $\ln (\mathrm{Y})=\ln (\mathrm{b} 0)+(\ln (\mathrm{b} 1) * \mathrm{t})$.

S-curve. $Y=e^{* *}(b 0+(b 1 / t))$ veya $\ln (Y)=b 0+(b 1 / t)$.

Growth. $Y=e^{* *}(b 0+(b 1 * t))$ veya $\ln (Y)=b 0+(b 1 * t)$.

Exponential. $Y=b 0 *\left(e^{* *}(b 1 * t)\right)$ veya $\ln (Y)=\ln (b 0)+(b 1 * t)$

Y=bağımlı değişken

$\mathrm{b}_{0}=$ Regresyon denklemi sabiti

$\mathrm{b}_{1}=$ Regresyon katsayısı

$\mathrm{t}=$ Bağımsız değişkenin değeri

Bu çerçevede, bağımlı değişkeni açıklayan bağımsız değişkenlerin oluşturduğu regresyon denkleminin belirleme katsayısı olan $\mathrm{R}^{2 \prime}$ nin daha yüksek olduğu modeli seçmek gerekmektedir. Bu nedenle eğri tahmininde bir takım farklı modeller kullanılmıştır. Bu modeller, Linear, Logarithmic, Inverse, Quadratic, Cubic, Power, Compound, S-curve, Growth ve Exponential'dir. Belirtilen modellerden, regresyon analizi sonucunda elde edilen ve belirlilik katsayısı en yüksek olan model seçilmiş ve değerlendirilmiştir. Çalışmada anlamlılık düzeyi $\alpha=0,05$ olarak gösterilmiştir. Veriler (SPSS, Chicago IL, Version 17) paket programında değerlendirilmiştir.

\section{ANALIZIN UYGULANMASI}

Analizin uygulanmasında daha evvel bahsedildiği gibi her ülkenin CDS verileri bağımsız değişken, endeks kapanışları ise bağımlı değişken olarak dikkate alınmış ve her ülke için ayrı ayrı eğri tahmini yapılarak model hesaplanmaya çalışılmıştır. Tüm olası regresyon eğrilerinin tahmini yapılacağından, veriler ayrıca normallik testine tabi tutulmamıştır.

Analiz yapılırken kullanılan temel hipotez aşağıda yer almaktadır.

$\mathrm{H}_{0}=\mathrm{CDS}$ primleri endeks kapanışlarını etkilememektedir.

Temel varsayım test edildiğinde bulunan $\mathrm{P}$ değeri (Sig.) $<0,05$ ise $\mathrm{H}_{0}$ hipotezi red edilecek ve CDS primlerinin kapanış endeksini etkilediğini ifade eden $\mathrm{H}_{1}$ hipotezi kabul edilecektir.

\subsection{Türkiye İçin Oluşturulan Model}

Türkiye'nin risk primine dayanılarak borsa kapanış endeksini hesaplamak için oluşturulacak modelin tahmini içi yapılan analiz sonuçları aşağıdaki tabloda gösterilmektedir. 
Tablo 1: Türkiye CDS Primleri ve Endeks Kapanışları Arasındaki İlişkiyi Gösteren Regresyon Eğri Tahminleri

\begin{tabular}{|c|c|c|c|c|c|c|c|c|c|}
\hline \multirow[t]{2}{*}{ Eğri Tahminleri } & \multicolumn{5}{|c|}{ Model Tahminleri } & \multicolumn{4}{|c|}{ Katsayı Tahminleri } \\
\hline & R Square & $\mathrm{F}$ & sd1 & $\mathrm{sd} 2$ & Olasılık & Sabit & b1 & b2 & b3 \\
\hline Linear-Doğrusal & ,322 & 597,047 & 1 & 1258 & ,000 & 89295,904 & $-140,350$ & & \\
\hline $\begin{array}{l}\text { Logarithmic } \\
\text { Logaritmik }\end{array}$ & 344 & 659,533 & 1 & 1258 & 000 & 211892,591 & $-28610,578$ & & \\
\hline Inverse Ters & 362 & 713,563 & 1 & 1258 & ,000 & 32288,469 & 5431720,494 & & \\
\hline Quadratic & ,338 & 321,061 & 2 & 1257 & ,000 & 112599,498 & $-378,767$ & ,573 & \\
\hline Cubic & ,402 & 280,863 & 3 & 1256 &, 000 & 266877,262 & $-2733,321$ & 12,02 &,- 018 \\
\hline Compound & 311 & 568,298 & 1 & 1258 & ,000 & 97184,917 & 998 & & \\
\hline Power & 321 & 594,845 & 1 & 1258 & 000 & 769664,345 &,- 485 & & \\
\hline S & ,326 & 608,997 & 1 & 1258 & ,000 & 10,519 & 90,447 & & \\
\hline Growth & 311 & 568,298 & 1 & 1258 & 000 & 11,484 &,- 002 & & \\
\hline Exponentiall & 311 & 568,298 & 1 & 1258 & ,000 & 97184,917 &,- 002 & & \\
\hline
\end{tabular}

Tablodan da görüldüğü gibi her model için bulunan $\mathrm{P}$ değerleri $<0,05$ olduğundan $\mathrm{H}_{1}$ hipotezi kabul edilecektir. Regresyon eğrileri incelendiğinde $R^{2 \text { s }}$ si 0,402 ile en yüksek olan Cubic modelin seçilmesi uygun olmaktadır. Cubic eğri denklemi aşağıdaki şekilde ifade edilmektedir. Cubic eğri formülünü Türkiye için oluşturulacak modele uyarladığımızda bu eğrinin denklemi aşağıda yazılmıştır.

Turkiyekapanis $=266877,262-2733,32 *$ turkiyecds $+12,023 *$ turkiyecds $^{2}-0,018 *$ turkiyecds $^{3}$ Türkiye'deki CDS primleri ile endeks kapanış değerleri arasındaki ilişki aşağıdaki grafikte gösterilmektedir.

\section{Şekil 2: Türkiye CDS Primleri ve Endeks Kapanışları Arasındaki Illişkinin Dağılım Grafiği}

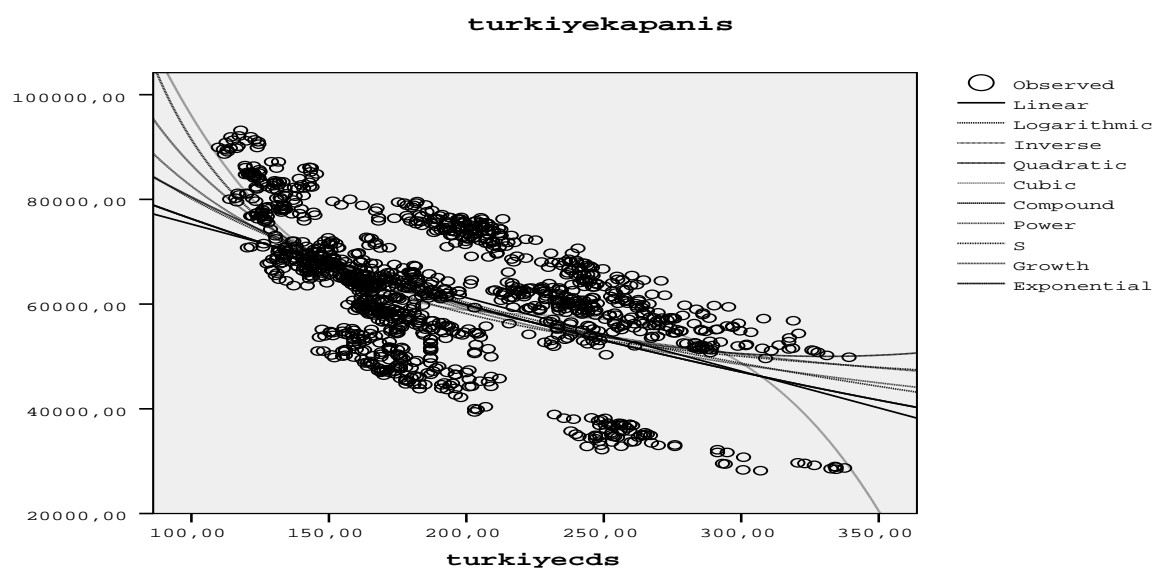


Şekil 2 ile verilen dağılım grafiği incelendiğinde Türkiye CDS primleri ile endeks kapanış değerlerinin dağılımına en uygun modelin cubic model olduğu grafiksel olarak da görülmektedir. Bu durumda Türkiye CDS primleri ile endeks kapanış değerleri arasında eğrisel bir ilişki olduğu ve bu ilişkinin cubic modele uyduğu değerlendirilebilir.

\subsection{Rusya İçin Oluşturulan Model}

Rusya'nın risk primine (CDS) dayanılarak borsa kapanış endeksini hesaplamak için oluşturulacak modelin tahmini içi yapılan analiz sonuçları aşağıdaki tabloda gösterilmektedir.

Tablo 2: Rusya CDS Primleri ve Endeks Kapanışları Arasındaki ilişkiyi Gösteren Regresyon Eğri Tahminleri

\begin{tabular}{|c|c|c|c|c|c|c|c|c|c|}
\hline \multirow[t]{2}{*}{ Eğri Tahminleri } & \multicolumn{5}{|c|}{ Model Tahminleri } & \multicolumn{4}{|c|}{ Katsayı Tahminleri } \\
\hline & R Square & $\mathrm{F}$ & df1 & df2 & Sig. & Constant & b1 & b2 & b3 \\
\hline Linear & ,536 & 1444,317 & 1 & 1251 & 000 & 2099,983 & $-3,375$ & & \\
\hline Logarithmic & ,541 & 1475,968 & 1 & 1251 & ,000 & 5125,316 & $-703,604$ & & \\
\hline Inverse & ,531 & 1414,665 & 1 & 1251 & ,000 & 704,245 & 134036,144 & & \\
\hline Quadratic & ,538 & 728,041 & 2 & 1250 & ,000 & 2244,017 & $-4,787$ & ,003 & \\
\hline Cubic & ,554 & 516,191 & 3 & 1249 & ,000 & 3385,967 & $-21,034$ & ,076 & ,000 \\
\hline Compound &, 598 & 1862,649 & 1 & 1251 &, 000 & 2326,435 & ,997 & & \\
\hline Power & ,581 & 1736,736 & 1 & 1251 & ,000 & 21434,913 &,- 519 & & \\
\hline S & ,549 & 1524,370 & 1 & 1251 & 000 & 6,725 & 96,979 & & \\
\hline Growth & ,598 & 1862,649 & 1 & 1251 & ,000 & 7,752 &,- 003 & & \\
\hline Exponential & ,598 & 1862,649 & 1 & 1251 & ,000 & 2326,435 &,- 003 & & \\
\hline
\end{tabular}

Tablodan da görüldüğü gibi her model için bulunan $\mathrm{P}$ değerleri $<0,05$ olduğundan $\mathrm{H}_{1}$ hipotezi kabul edilecektir. Regresyon eğrileri incelendiğinde $\mathrm{R}^{2{ }^{2}}$ si 0,598 ile en yüksek olan Compound modelin seçilmesi uygun olmaktadır. Bu eğrinin denklemi aşağıda yazıımıştır.

Rusyakapanis $=2326,435 *\left(0,997^{\text {rusyacds }}\right)$

Rusya'nın CDS primleri ile endeks kapanış değerleri arasındaki ilişki aşağıdaki grafikte gösterilmektedir; 


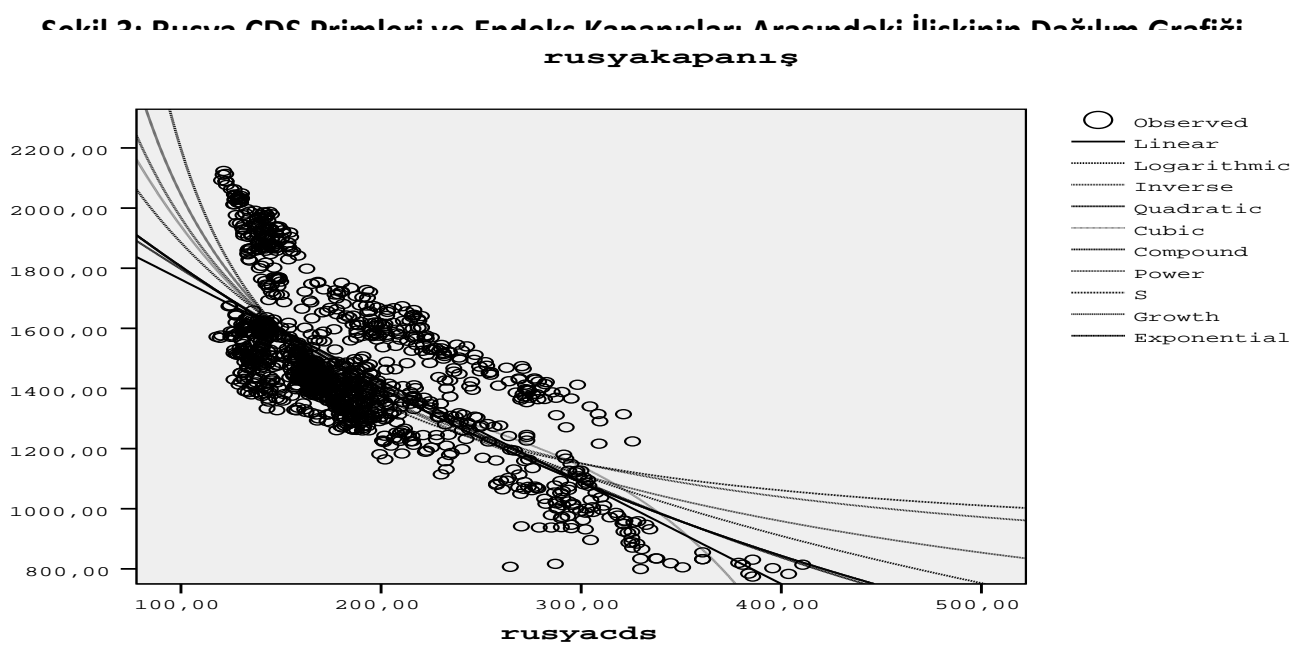

Şekil 3 ile verilen dağılım grafiği incelendiğinde, Rusya CDS primleri ile endeks kapanış değerlerinin dağılımına en uygun modelin compound model olduğu grafiksel olarak da görülmektedir. Bu durumda Rusya CDS primleri ile endeks kapanış değerleri arasında eğrisel bir ilişki olduğu ve bu ilişkinin compound modele uyduğu değerlendirilebilir.

\subsection{Arjantin İçin Oluşturulan Model}

Arjantin'in risk primine dayanılarak borsa kapanış endeksini hesaplamak için oluşturulacak modelin tahmini içi yapılan analiz sonuçları aşağıdaki tabloda gösterilmektedir.

Tablo 3: Arjantin CDS Primleri ve Endeks Kapanışları Arasındaki iliş̧kiyi Gösteren Regresyon Eğri Tahminleri

\begin{tabular}{|c|c|c|c|c|c|c|c|c|c|}
\hline \multirow[t]{2}{*}{ Eğri Tahminleri } & \multicolumn{5}{|c|}{ Model Tahminleri } & \multicolumn{4}{|c|}{ Katsayı Tahminleri } \\
\hline & R Square & $\mathrm{F}$ & df1 & $\mathrm{df} 2$ & Sig. & Constant & b1 & b2 & b3 \\
\hline Linear & ,018 & 22,971 & 1 & 1239 & ,000 & 5160,575 &,- 950 & & \\
\hline Logarithmic & ,096 & 131,675 & 1 & 1239 & ,000 & 26660,861 & $-3221,769$ & & \\
\hline Inverse & ,392 & 797,570 & 1 & 1239 & 000 & $-2457,326$ & 6417901,146 & & \\
\hline Quadratic & 099 & 68,167 & 2 & 1238 & ,000 & 11177,987 & $-9,790$ &, 002 & \\
\hline Cubic & 293 & 171,179 & 3 & 1237 & ,000 & 26304,264 & $-41,574$ & ,020 & $-2,90 \mathrm{E}-006$ \\
\hline Compound & 001 & ,780 & 1 & 1239 & 377 & 3055,923 & 1,000 & & \\
\hline Power & ,034 & 42,977 & 1 & 1239 & ,000 & 9125,388 &,- 157 & & \\
\hline$S$ & ,216 & 340,424 & 1 & 1239 & ,000 & 7,620 & 393,151 & & \\
\hline Growth & 001 & 780 & 1 & 1239 & 377 & 8,025 & $-1,46 \mathrm{E}-005$ & & \\
\hline Exponential & 604 & 1893,233 & 1 & 1239 & , 000 & 86909,243 &,- 003 & & \\
\hline
\end{tabular}

Tablodan da görüldüğü gibi çoğu model için bulunan $P$ değerleri $<0,05$ olduğundan $\mathrm{H}_{1}$ hipotezi kabul edilecektir. Regresyon eğrileri incelendiğinde $R^{2 \text { s }}$ si 0,392 ile en yüksek olan Inverse modelin seçilmesi uygun olmaktadır. Bu eğrinin denklemi aşağıda yazılmıştır. 
arjantinkapanis $=-2457,326+(6417901,146 /$ arjantincds $)$

Arjantin'deki CDS primleri ile endeks kapanış değerleri arasındaki ilişki aşağıdaki grafikte gösterilmektedir;

\section{Şekil 4: Arjantin CDS Primleri ve Endeks Kapanışları Arasındaki iliş̧kinin Dağılım Grafiği}

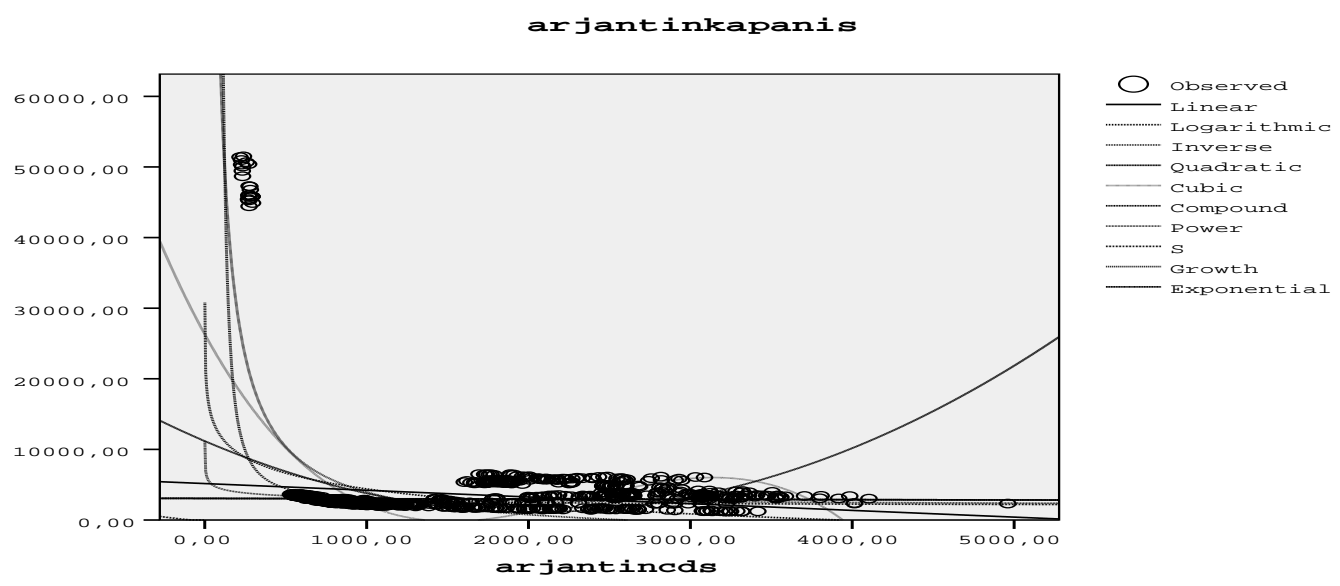

Şekil 4 ile verilen dağılım grafiği incelendiğinde, Arjantin CDS primleri ile endeks kapanış değerlerinin dağılımına en uygun modelin inverse model olduğu grafiksel olarak da görülmektedir. Bu durumda Arjantin CDS primleri ile endeks kapanış değerleri arasında eğrisel bir ilişki olduğu ve bu ilişkinin inverse modele uyduğu değerlendirilebilir.

\subsection{Brezilya İçin Oluşturulan Model}

Brezilya'nın risk primine dayanılarak borsa kapanış endeksini hesaplamak için oluşturulacak modelin tahmini içi yapılan analiz sonuçları aşağıdaki tabloda gösterilmektedir.

Tablo 4: Brezilya CDS Primleri ve Endeks Kapanışları Arasındaki iliş̧iyi Gösteren Regresyon Eğri Tahminleri

\begin{tabular}{|c|c|c|c|c|c|c|c|c|c|}
\hline \multirow[t]{2}{*}{ Eğri Tahminleri } & \multicolumn{5}{|c|}{ Model Tahminleri } & \multicolumn{4}{|c|}{ Katsayı Tahminleri } \\
\hline & R Square & $\mathrm{F}$ & df1 & $\mathrm{df} 2$ & Sig. & Constant & b1 & b2 & b3 \\
\hline Linear & ,580 & 1709,180 & 1 & 1239 & ,000 & 81585,166 & $-157,840$ & & \\
\hline Logarithmic & ,599 & 1850,504 & 1 & 1239 & ,000 & 180765,421 & $-24664,134$ & & \\
\hline Inverse & ,590 & 1785,183 & 1 & 1239 & ,000 & 32934,007 & 3547954,899 & & \\
\hline Quadratic & 607 & 957,548 & 2 & 1238 & ,000 & 98152,071 & $-374,283$ & ,664 & \\
\hline Cubic & 613 & 652,080 & 3 & 1237 & ,000 & 70960,921 & 126,189 & $-2,246$ & ,005 \\
\hline Compound & ,604 & 1893,233 & 1 & 1239 & ,000 & 86909,243 & 997 & & \\
\hline Power & 619 & 2015,367 & 1 & 1239 &, 000 & 487182,887 &,- 429 & & \\
\hline$S$ & ,606 & 1903,539 & 1 & 1239 & ,000 & 10,526 & 61,490 & & \\
\hline Growth & 604 & 1893,233 & 1 & 1239 & ,000 & 11,373 &,- 003 & & \\
\hline Exponential & ,604 & 1893,233 & 1 & 1239 &, 000 & 86909,243 &,- 003 & & \\
\hline
\end{tabular}


Tablodan da görüldüğü gibi her model için bulunan $\mathrm{P}$ değerleri $<0,05$ olduğundan $\mathrm{H}_{1}$ hipotezi kabul edilecektir. Regresyon eğrileri incelendiğinde $R^{2 \text { s }}$ si 0,619 ile en yüksek olan Power modelin seçilmesi uygun olmaktadır. Bu eğrinin denklemi aşağıda yazıımıştır.

brezilyakapanis $=487182,887 *\left(\right.$ brezilyacds $\left.^{-0,429}\right)$

Brezilya'daki CDS primleri ile endeks kapanış değerleri arasındaki ilişki aşağıdaki grafikte gösterilmektedir;

\section{Şekil 5: Brezilya CDS Primleri ve Endeks Kapanışları Arasındaki iliş̧kinin Dağılım Grafiği}

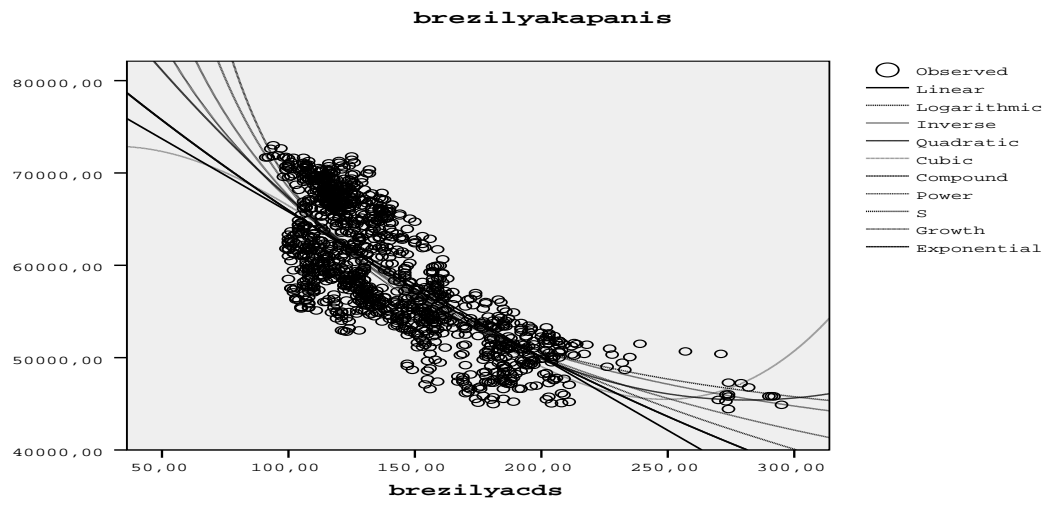

Şekil 5 ile verilen dağılım grafiği incelendiğinde Brezilya CDS primleri ile endeks kapanış değerlerinin dağılımına en uygun modelin power model olduğu grafiksel olarak da görülmektedir. Bu durumda Brezilya CDS primleri ile endeks kapanış değerleri arasında eğrisel bir ilişki olduğu ve bu ilişkinin power modele uyduğu değerlendirilebilir.

\subsection{Malezya İçin Oluşturulan Model}

Malezya'nın risk primine dayanılarak borsa kapanış endeksini hesaplamak için oluşturulacak modelin tahmini içi yapılan analiz sonuçları aşağıdaki tabloda gösterilmektedir.

Tablo 5: Malezya CDS Primleri ve Endeks Kapanışları Arasındaki ilişkiyi Gösteren Regresyon Eğri Tahminleri

\begin{tabular}{|c|c|c|c|c|c|c|c|c|c|}
\hline \multirow[t]{2}{*}{ Eğri Tahminleri } & \multicolumn{5}{|c|}{ Model Tahminleri } & \multicolumn{4}{|c|}{ Katsayı Tahminleri } \\
\hline & R Square & $\mathrm{F}$ & df1 & $\mathrm{df} 2$ & Sig. & Constant & b1 & b2 & b3 \\
\hline Linear & ,381 & 774,107 & 1 & 1257 & ,000 & 1857,006 & $-3,459$ & & \\
\hline Logarithmic & ,230 & 374,785 & 1 & 1257 & ,000 & 3586,659 & $-455,000$ & & \\
\hline Inverse & 107 & 150,821 & 1 & 1257 & ,000 & 1101,629 & 37406,017 & & \\
\hline Quadratic & ,428 & 470,186 & 2 & 1256 & ,000 & 1552,317 & ,455 &,- 008 & \\
\hline Cubic & ,477 & 382,239 & 3 & 1255 & ,000 & 960,059 & 12,206 &,- 073 & $9,08 \mathrm{E}-005$ \\
\hline Compound & ,706 & 3023,709 & 1 & 1257 &, 000 & 3471,946 & ,992 & & \\
\hline Power & ,406 & 857,585 & 1 & 1257 & ,000 & 210237,833 & $-1,085$ & & \\
\hline S & 182 & 279,083 & 1 & 1257 & ,000 & 6,347 & 87,432 & & \\
\hline
\end{tabular}




\begin{tabular}{|l|r|r|r|r|r|r|r|r|} 
Growth &, 706 & 3023,709 & 1 & 1257 &, 000 & 8,152 &,- 008 \\
Exponential &, 706 & 3023,709 & 1 & 1257 &, 000 & 3471,946 &,- 008 & \\
\hline
\end{tabular}

Tablodan da görüldüğü gibi her model için bulunan $\mathrm{P}$ değerleri $<0,05$ olduğundan $\mathrm{H}_{1}$ hipotezi kabul edilecektir. Regresyon eğrileri incelendiğinde $R^{2,}$ si 0,706 ile en yüksek olan Compound modelin seçilmesi uygun olmaktadır. Bu eğrinin denklemi aşağıda yazıımıştır.

malezyakapanis $=3471,946 *\left(0,992^{\text {malezyacds }}\right)$

Malezya'daki CDS primleri ile endeks kapanış değerleri arasındaki ilişki aşağıdaki grafikte gösterilmektedir;

\section{Şekil 6: Malezya CDS Primleri ve Endeks Kapanışları arasındaki İlişkinin Dağılım Grafiği}

malezyakapanis

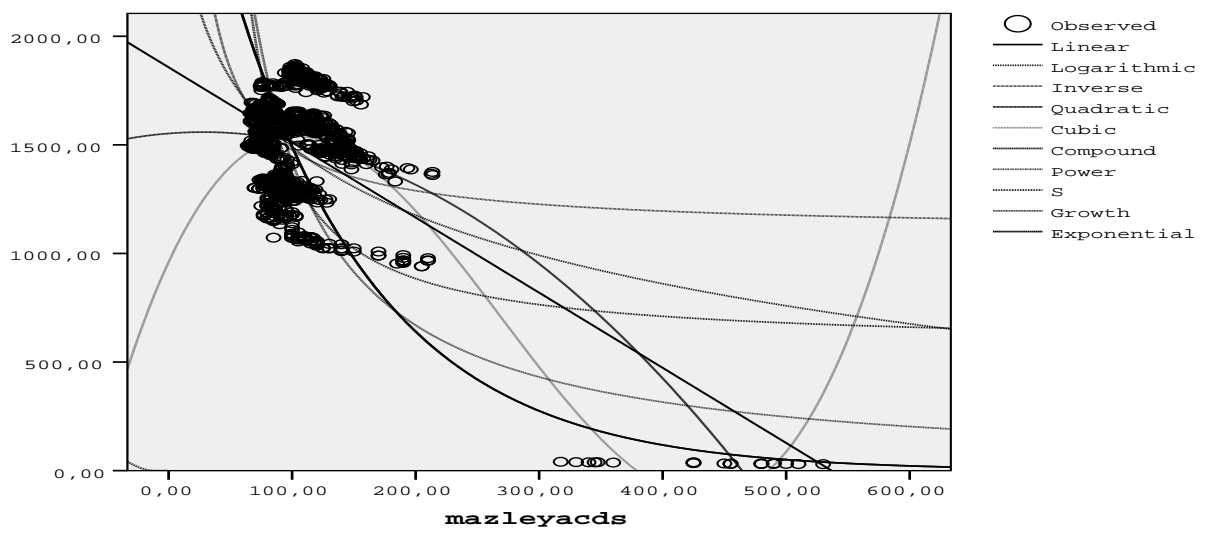

Şekil 6 ile verilen dağılım grafiği incelendiğinde Malezya CDS primleri ile endeks kapanış değerlerinin dağılımına en uygun modelin compound model olduğu grafiksel olarak da görülmektedir. Bu durumda Malezya CDS primleri ile endeks kapanış değerleri arasında eğrisel bir ilişki olduğu ve bu ilişkinin compound modele uyduğu değerlendirilebilir.

\subsection{Endonezya İçin Oluşturulan Model}

Endonezya'nın risk primine dayanılarak borsa kapanış endeksini hesaplamak için oluşturulacak modelin tahmini içi yapılan analiz sonuçları aşağıdaki tabloda gösterilmektedir.

Tablo 6: Endonezya CDS Primleri ve Endeks Kapanışları Arasındaki i̇lişkiyi Gösteren Regresyon Eğri Tahminleri

\begin{tabular}{|c|c|c|c|c|c|c|c|c|c|}
\hline \multirow[t]{2}{*}{ Eğri Tahminleri } & \multicolumn{5}{|c|}{ Model Tahminleri } & \multicolumn{4}{|c|}{ Katsayı Tahminleri } \\
\hline & R Square & $\mathrm{F}$ & df1 & $\mathrm{df} 2$ & Sig. & Constant & b1 & b2 & b3 \\
\hline Linear & ,030 & 38,335 & 1 & 1258 & ,000 & 53,510 &,- 063 & & \\
\hline Logarithmic & ,033 & 43,125 & 1 & 1258 & , 000 & 116,754 & $-14,446$ & & \\
\hline Inverse & 032 & 41,319 & 1 & 1258 & ,000 & 26,203 & 2707,764 & & \\
\hline Quadratic & ,036 & 23,424 & 2 & 1257 & ,000 & 66,244 &,- 179 & ,000 & \\
\hline Cubic & ,036 & 15,660 & 3 & 1256 & , 000 & 60,925 &,- 109 & $-4,76 \mathrm{E}-005$ & $3,35 \mathrm{E}-007$ \\
\hline
\end{tabular}




\begin{tabular}{|l|r|r|r|r|r|r|r|} 
Compound &, 022 & 28,545 & 1 & 1258 &, 000 & 46,754 &, 999 \\
Power &, 026 & 33,741 & 1 & 1258 &, 000 & 155,220 &,- 273 \\
S &, 026 & 33,219 & 1 & 1258 &, 000 & 3,330 & 51,823 \\
Growth &, 022 & 28,545 & 1 & 1258 &, 000 & 3,845 &,- 001 \\
Exponential &, 022 & 28,545 & 1 & 1258 &, 000 & 46,754 &,- 001 \\
\hline
\end{tabular}

Tablodan da görüldüğü gibi her model için bulunan $\mathrm{P}$ değerleri $<0,05$ olduğundan $\mathrm{H}_{1}$ hipotezi kabul edilecektir. Ancak regresyon eğrileri incelendiğinde $R^{2}$ değerlerinin oldukça küçük olduğu görülmektedir. Bu durumda Endonezya'nın CDS primlerinin kapanış endeksini açıklama gücü zayıf kabul edilerek aralarındaki ilişkinin önemsiz olduğu söylenebilir.

Endonezya'daki CDS primleri ile endeks kapanış değerleri arasındaki ilişki aşağıdaki grafikte gösterilmektedir;

\section{Şekil 7: Endonezya CDS Primleri ve Endeks Kapanışları arasındaki illişkinin Dağılım Grafiği}

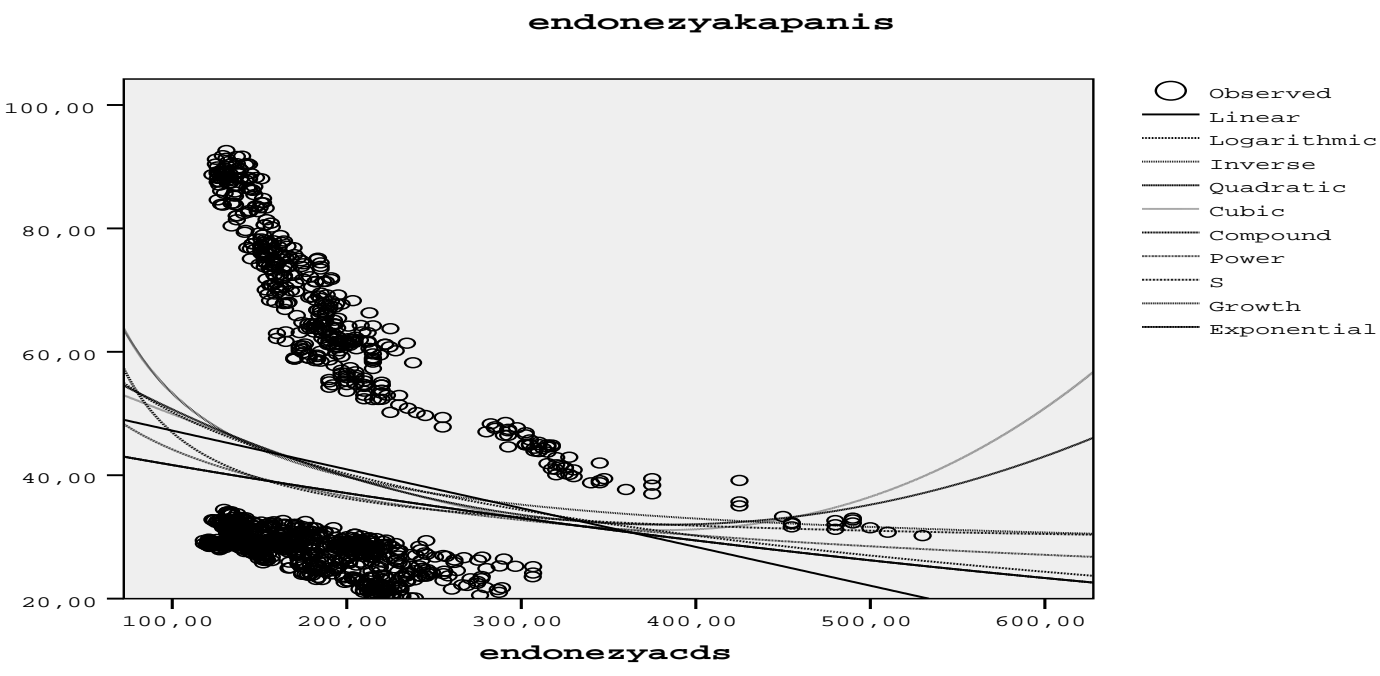

Şekil 7 ile verilen dağılım grafiği incelendiğinde, Endonezya CDS primleri ile endeks kapanış değerlerinin dağılımı arasında zayıf ilişki bulunmakta olup, çıkan sonuçlara göre düşük ilişki seviyeleri içinde en üst sıra cubic model olduğu grafiksel olarak da görülmektedir. Ancak analiz sonuçlarının gösterdiği gibi, bu ilişkinin zayıf olması nedeniyle denklem yazmanın anlamsızlığı dikkate alınarak bu ülke için denklem oluşturulmamıştır.

\section{7. Çin İçin Oluşturulan Model}

Çin'in risk primine dayanılarak borsa kapanış endeksini hesaplamak için oluşturulacak modelin tahmini içi yapılan analiz sonuçları aşağıdaki tabloda gösterilmektedir. 
Tablo 7: Çin CDS Primleri ve Endeks Kapanışları Arasındaki ilişsiyi Gösteren Regresyon Eğri Tahminleri

\begin{tabular}{|c|c|c|c|c|c|c|c|c|c|}
\hline \multirow[t]{2}{*}{ Eğri Tahminleri } & \multicolumn{5}{|c|}{ Model Tahminleri } & \multicolumn{4}{|c|}{ Katsayı Tahminleri } \\
\hline & R Square & $\mathrm{F}$ & df1 & $\mathrm{df} 2$ & Sig. & Constant & b1 & b2 & b3 \\
\hline Linear & 149 & 218,534 & 1 & 1244 &, 000 & 3052,599 & $-5,864$ & & \\
\hline Logarithmic & 163 & 242,641 & 1 & 1244 & , 000 & 5141,774 & $-586,448$ & & \\
\hline Inverse & 168 & 250,441 & 1 & 1244 & ,000 & 1891,803 & 53087,884 & & \\
\hline Quadratic & 181 & 137,184 & 2 & 1243 & ,000 & 3970,647 & $-25,438$ & ,096 & \\
\hline Cubic & 184 & 93,630 & 3 & 1242 & ,000 & 2996,932 & 4,965 &,- 204 & ,001 \\
\hline Compound & 138 & 198,698 & 1 & 1244 & ,000 & 3044,931 & 998 & & \\
\hline Power & 151 & 221,407 & 1 & 1244 & ,000 & 6680,851 &,- 220 & & \\
\hline$S$ & 155 & 228,973 & 1 & 1244 & ,000 & 7,585 & 19,977 & & \\
\hline Growth & 138 & 198,698 & 1 & 1244 & ,000 & 8,021 &,- 002 & & \\
\hline Exponential & 138 & 198,698 & 1 & 1244 & ,000 & 3044,931 &,- 002 & & \\
\hline
\end{tabular}

Tablodan da görüldüğü gibi her model için bulunan $\mathrm{P}$ değerleri $<0,05$ olduğundan $\mathrm{H}_{1}$ hipotezi kabul edilecektir. Ancak regresyon eğrileri incelendiğinde $R^{2}$ değerlerinin oldukça küçük olduğu görülmektedir. Bu durumda Çin'in CDS primlerinin kapanış endeksini açıklama gücü zayıf kabul edilerek aralarındaki ilişkinin önemsiz olduğu söylenebilir.

Çin'deki CDS primleri ile endeks kapanış değerleri arasındaki ilişki aşağıdaki grafikte gösterilmektedir;

\section{Şekil 8: Çin CDS Primleri ve Endeks Kapanışları arasındaki ilişsinin Dağılım Grafiği}

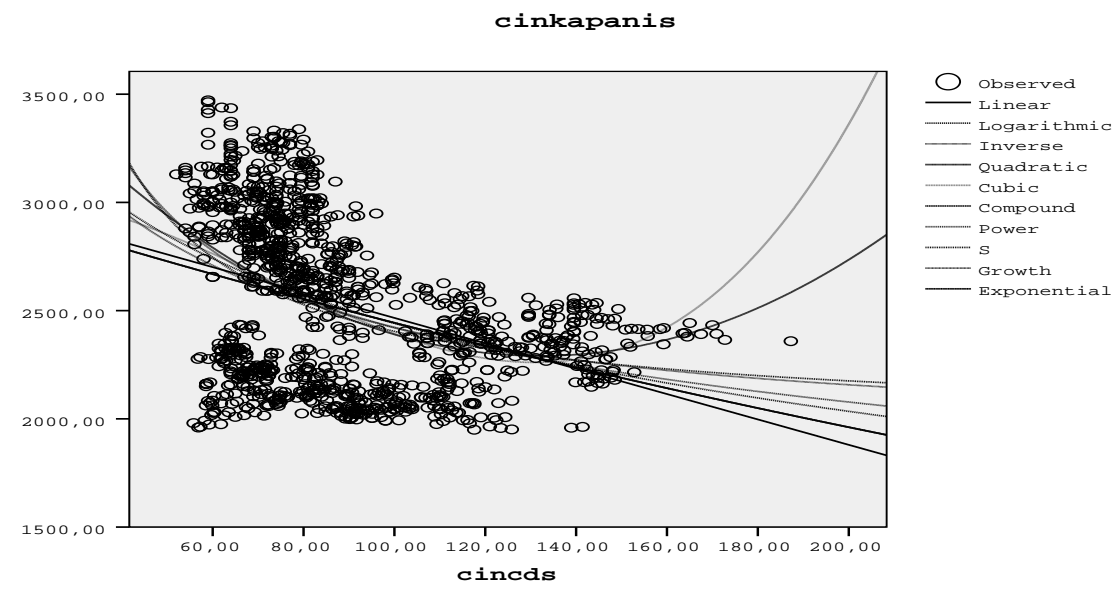

Şekil 8 ile verilen dağılım grafiği incelendiğinde, Endonezya'da olduğu gibi Çin CDS primleri ile endeks kapanış değerlerinin dağılımı arasında zayıf ilişki bulunmakta olup, çıkan sonuçlara göre düşük ilişki seviyeleri içinde en üst sıra cubic model olduğu grafiksel olarak da görülmektedir. Ancak analiz sonuçlarının gösterdiği gibi, bu ilişkinin zayıf olması nedeniyle denklem yazmanın anlamsızlığı dikkate alınarak bu ülke için de denklem oluşturulmamıştır. 


\section{SONUÇ}

Son yıllarda giderek artan önemi ve kabul görmüşlüğü dikkate alınarak önemli bir gösterge haline gelmeye başlayan Kredi Temerrüt Swapları, gelecek vaad eden bir gösterge olarak ifade edilebilir. Etkileşimin üst seviyelere çıktığı finansal piyasalarda, CDS'ler yatırımcıların yön bulmalarında giderek artan öneme sahip olmaktadır.

Ülkelerin CDS primleri ile finansal verileri arasındaki ilişki ve etkileşim konusunda yapılan çalışmalar genellikle tek ülke bazında gerçekleştirilmiş olup, bu çalışmada 7 farklı ülkedeki ilişkinin ayrı ayrı değerlendirilmesi, ayrıca bu ülkelerin gelişmekte olan ülke olması ve büyüme potansiyeli taşıması, elde edilen bulgulara göre de ülkeler arası benzerlik / farklılığa dikkat çekilme eğilimi bu çalışmanın farklıığını oluşturmaktadır.

Hassasiyetin daha yüksek olduğu gelişmekte olan ülke piyasalarında iki önemli gösterge arasındaki ilişkinin varlığı ile, ülkelerarası benzerlik ve farklılıkların araştırıldığı bu çalışma 7 ülke açısından gerçekleştirilmiştir.

Bu kapsamda, sözkonusu 7 ülkeye ilişkin CDS primleri ile aynı ülkelerin gösterge borsa endekslerinin kapanışları arasındaki ilişki regresyon eğrisi tahmin modelleriyle belirlenmeye çalışılmıştır. Çalışmada yapılan analizler sonucu her bir ülke için elde edilen en uygun modele göre CDS primlerinin endeks değerlerini açıklama oranları aşağıdaki tabloda verilmiştir.

Tablo 8: Ülkelerin CDS Primleri ile Endeks Kapanışları Arasındaki İlişki Düzeyi

\begin{tabular}{|l|c|}
\hline Ülke & $\mathbf{R}^{\mathbf{2}}$ \\
\hline Malezya & 0,76 \\
\hline Brezilya & 0,619 \\
\hline Rusya & 0,598 \\
\hline Türkiye & 0,402 \\
\hline Arjantin & 0,392 \\
\hline Çin & 0,184 \\
\hline Endonezya & 0,036 \\
\hline
\end{tabular}

Analiz sonucunda elde edilen bulgulara göre, risk göstergesi niteliğindeki CDS primleri ile borsa arasında en hassas ilişki Malezya'da görülürken, sırasıyla Brezilya ve Rusya'da sözkonusu ilişkinin gücünü koruduğu ifade edilebilir.

Türkiye açısından CDS pirimi ile borsa endeksi arasındaki hassasiyet orta seviyelerde elde edilmiştir. Sözkonusu ilişki Arjantin ve sonrasında Çin'de giderek azalan bir seyir izlerken, Endonezya'da bu ilişkinin gözardı edilebileceği sonucuna ulaşılmıştır.

Morgan Stanley tarafından hazırlanan 1 Ağustos 2013 tarihli raporda ise Brezilya, Endonezya, Güney Afrika, Hindistan ve Türkiye "Kırılgan Beşli" olarak gruplandırılmıştır. Kırılgan Beşli gruplandırmasının temelinde bu ülkelerin yüksek cari açık oranları, yüksek enflasyon oranları ve büyüme performanslarındaki istikrarsızlık gibi nedenler bulunmaktadır. Şili, Macaristan, 
Arjantin, Rusya ve Polonya'nın eklenmesiyle kırılgan olarak isimlendirilen ülke grubu genişletilmiştir.

Bu çerçevede, çalışmanın hipotezinde belirtildiğinden farklı bulgular elde edilmiştir. Çünkü, çalışma kapsamındaki ülkeler incelendiğinde, bazıları kırılgan olarak nitelendirilen ülkeler olup, bazılarının ise gelişmekte olan ekonomiler grubunda yer aldığı görülmektedir. CDS primleri ile borsa endeksi arasındaki ilişki açısından kırılgan ülkeler grubunda yer almayan Malezya'nın en hassas, kırılgan ülkeler grubunda yer alan Endonezya'nın ise aksine en düşük hassasiyete sahip sonuçları verdiği görülmektedir. Türkiye açısından ilişkinin ne çok güçlü ne de aşırı güçsüz çıkmamasına neden olan sebepleri arasında, sık yaşanan krizler sonucunda alınan önlemler olduğu düşünülmektedir.

\section{KAYNAKLAR}

Alper, D. (2011). Kredi Iflas Takası CDS. Bursa: Ekin Yayınları.

Balı, S., \& Yılmaz, Z.(2012). Kredi temerrüt takası marjları ile IMKB 100 endeksi arasındaki ilişki. XVI. Finans Sempozyumunda Sunulmuş Bildiri.

Chen, L. H., Hammoudeh, S., \& Yuan, Y. (2011). Asymmetric convergence in US financial credit default swap sector index markets. The Quarterly Review of Economics and Finance, 51(4), 408-418.

Erbaş, S. O. (2013). Olasılık ve Istatistik. Ankara: Gazi.

Ersan, İ., \& Günay, S. (2009). Kredi Riski Göstergesi Olarak Kredi Temerrüt Swapları (CDSs) ve Kapatma Davasının Türkiye Riski Üzerine Etkisine Dair Bir Uygulama. Bankacılar Dergisi, 71, 3-22.

Fung, H. G., Sierra, G. E., Yau, J., \& Zhang, G. (2008). Are the US stock market and credit default swap market related? Evidence from the CDX indices. The Journal of Alternative Investments, 11(1), 43-61.

Hassan, M. K., Ngow, T. S., Yu, J. S., \& Hassan, A. (2013). Determinants of credit default swaps spreads in European and Asian markets. Journal of Derivatives \& Hedge Funds, 19(4), 295-310.

Karabıyık, L., \& Anbar, A. (2006). Kredi Temerrüt Swapları ve Kredi Temerrüt Swaplarının Fiyatlandırılması. Muhasebe ve Finansman Dergisi, 31, 49-60.

Keten, M., Başarır, Ç., \& Kılıç, Y. (2013). Kredi Temerrüt Takası İle Makroekonomik Ve Finansal Değişkenler Arasındaki İlişkinin İncelenmesi. XVII. Finans Sempozyumunda Sunulmuş Bildiri.

Kunt, A. S., \& Taş, O. (2009). Kredi temerrüt swapları ve Türkiye'nin CDS priminin tahmin edilmesine yönelik bir uygulama. ITÜDERGisi/b, 5(1).

Norden, L., \& Weber, M. (2004). Informational efficiency of credit default swap and stock markets: The impact of credit rating announcements. Journal of Banking \& Finance, 28(11), 2813-2843.

Norden, L., \& Weber, M. (2009). The co-movement of credit default swap, bond and stock markets: an empirical analysis. European financial management,15(3), 529-562.

Sensoy, A., Soytas, U., Yildirim, I., \& Hacihasanoglu, E. (2014). Dynamic relationship between Turkey and European countries during the global financial crisis. Economic Modelling, 40, 290-298.

Terzi, N., \& Ulucay, K. (2011). The role of credit default swaps on financial market stability. Procedia -Social and Behavioral Sciences, 24, 983-990.

Tözüm, H. (2009). Kredi Türevleri Uygulamada CDS'ler. Ankara: Dumat Ofset

Turguttopbaş, N. (2013). Kredi Temerrüt Swapları ve İlgili Riskin Gerçekleşmesi Durumunda Uygulanan Hukuki Prosedür. Bankacılar Dergisi, 84, $37-53$.

Zhu, H. (2006). An empirical comparison of credit spreads between the bond market and the credit default swap market. Journal of Financial Services Research, 29(3), 211-235.

http://finance.yahoo.com 